\title{
Common Clinical Practice for Low Back Pain Treatment: A Modified Delphi Study
}

\author{
Giustino Varrassi (D) - Biagio Moretti · Maria Caterina Pace • \\ Paolo Evangelista · Giovanni Iolascon
}

Received: November 11, 2020 / Accepted: February 16, 2021 / Published online: March 13, 2021

(c) The Author(s) 2021

\begin{abstract}
Introduction: Low back pain (LBP) is a common reason for adults to seek medical care and is associated with important functional limitation and patient burden. Yet, heterogeneity in the causes and presentation of LBP and a lack of standardization in its management impede effective prevention and treatment.
\end{abstract}

Supplementary Information The online version contains supplementary material available at https:// doi.org/10.1007/s40122-021-00249-w.

G. Varrassi $(\bowtie)$

Paolo Procacci Foundation, Rome, Italy

e-mail: giuvarr@gmail.com

B. Moretti

Orthopedic and Trauma Unit, Department of Basic Medical Sciences, Neuroscience and Sense Organs, School of Medicine, University of Bari "Aldo Moro", Bari, BA, Italy

M. C. Pace

Department of Women, Child, General and Specialist Surgery, "Luigi Vanvitelli", Naples, NA, Italy

P. Evangelista

Primary Care and Community Medicine, University of L'Aquila, L'Aquila, AQ, Italy

\section{G. Iolascon}

Department of Medical and Surgical Specialties and Dentistry, University of Campania "Luigi

Vanvitelli", Naples, NA, Italy
Methods: We conducted a modified Delphi study to generate consensus statements for the diagnosis, management, and prognosis of LBP. A panel of five experts proposed 19 statements that were subsequently evaluated by physicians who treat LBP in their everyday clinical practice. Physicians were asked to validate statements in the form of a web survey assessing level of agreement on a five-point Likert-like scale.

Results: Consensus ( $\geq 70 \%$ agreement) was obtained for all 19 statements. Strength of agreement and physician comments highlighted the importance of pain management, but also strategies to ameliorate functional limitation and prevent future LBP episodes. Respondents favored multidisciplinary approaches and multimodal management for LBP, although there was some ambiguity as to how multidisciplinary strategies could be feasibly incorporated into daily practice. Finally, the results indicated some conflict regarding the use of imaging for the diagnosis of LBP and how to classify LBP for targeted treatment.

Conclusion: The results of this study provide a summary of favored clinical practice for the management of chronic LBP. While the consensus statements were generally agreeable to survey respondents, some areas of ambiguity, including how to increase the feasibility of multidisciplinary strategies, when and how to use diagnostic imaging in LBP, and LBP classification, necessitate clarification in future studies and guidelines. 
Keywords: Chronic pain; Delphi study; Low back pain; Pain management; Rehabilitation

\section{Key Summary Points}

Why carry out this study?

Low back pain is very common and is now the leading cause of disability worldwide, with high costs and extensive health care use.

Low back pain is a common condition, with effects on well-being and impact on quality of life, and often low satisfaction with the treatments provided.

The objective of this study is to analyze the management of LBP in Italy and compare it with guideline recommendations.

\section{What was learned from the study?}

Physicians strongly agree with the use of multidisciplinary-multimodal approaches to provide comprehensive therapy that not only addresses pain, but also improves function.

The study highlighted the role of "personalized medicine" in patient management based on pain intensity, pain characteristics, specific pain generators, function, and quality of life.

Future efforts might include a content analysis designed to detect geographical differences in clinical practice and perceptions.

\section{DIGITAL FEATURES}

This article is published with digital features, including a summary slide, to facilitate understanding of the article. To view digital features for this article go to https://doi.org/10.6084/ m9.figshare.14039168.

\section{INTRODUCTION}

Low back pain (LBP) is a broad diagnostic term that encompasses a range of pathologies characterized by pain and discomfort below the costal margin and above the inferior gluteal folds $[1,2]$. LBP will affect one in two adults at some point during their lifetime, with peak prevalence among adults $40-50$ years of age [1] and significant prevalence among the elderly [3]. LBP can occur secondary to various pathologies $[4,5]$ or as a recurrent idiopathic pathology of the lumbar spine associated with pain and functional limitation. LBP is further classified based on the duration of symptoms as acute (4 weeks), subacute (4-12 weeks), or chronic (>3 months) [6]. Acute LBP is one of the most common reasons for adults to seek medical care. It becomes chronic in at least $10 \%$ of patients, with chronic LBP affecting approximately $6 \%$ of adults aged 20-69 years (incidence of 9.4 per 1000 person-years) [7]. In 2010, the World Health Organization ranked LBP as the sixth most burdensome condition, and in another report described LBP as the top cause of morbidity worldwide [8].

Despite its high incidence and prevalence and substantial global impact, chronic LBP remains poorly understood and difficult to diagnose, and is treated or prevented with variable efficacy [9]. With regard to its diagnosis, several guidelines have been proposed for detecting LBP and associated red flags, but there is little consensus regarding which red flags to endorse. There is some evidence supporting the diagnostic accuracy of red flags related to spinal fractures and spinal malignancies, but data are lacking regarding red flags for other conditions such as infection and ankylosing spondylitis. In terms of treatment, several evidence-based guidelines are available for the management of acute and chronic LBP. However, adherence to these recommendations and patient treatment satisfaction are low [10]. Studies suggest that more than a quarter of LBP care is inappropriate [11] and that care is generally insufficient in patients with comorbidities.

Given the current state of clinical LBP management, the goal of this modified Delphi study 
was to generate a series of consensus statements characterizing appropriate clinical practice for LBP; assess the degree to which physicians agree or disagree with these statements; and ultimately provide recommendations for improving clinical practice for LBP.

\section{METHODS}

\section{Study Design}

This study utilized a modified Delphi study design (structured Delphi consensus plus a qualitative feedback component) and was conducted over a period of 6 months from July to December 2019. Similar methods have been applied in previous studies to achieve consensus of opinion in a real-world context, including in health care environments [12, 13].

Consensus topics were elaborated by a scientific board composed of five experts in the area of pain medicine across a variety of specialties, including two pain physicians, one orthopedic surgeon, one specialist in rehabilitative medicine, and one general practitioner. The scientific board conducted an initial discussion at a face-to-face focus group based on a review of the literature and examination of national and international guidelines. At this meeting, the board elaborated 19 statements for use in a web-based survey to be administered to members of the board and an expanded panel of physicians who treat LBP in different care settings. Statements were designed to focus on possible disparities between clinical practice and guideline recommendations and on controversial ideas in LBP management. A complete list of these statements and the supporting bibliography are provided in Table 1 . The results of the survey were analyzed and discussed at a final face-to-face meeting at the end of the 6-month study period.

\section{Survey}

The survey consisted of 19 statements (S) graded on a five-point Likert-like scale $(1=$ "completely disagree"; 2 = "mostly disagree"; 3 = "somewhat
Table 1 Survey statements

1 It's essential to recognize the specific mechanisms that operate as pain generator in each patient to find a specific target of the therapeutic approach to control pain

2 Individual and psychosocial risk factors (such as female sex, younger age, high BMI, stress, depression, anxiety, and job dissatisfaction) are significantly associated with the transition from acute to chronic LBP. In their absence, patients can have healing reassurance; on the contrary, their presence conditions the care and the frequency of follow-up

3 Imaging isn't recommended for LBP within the first 6 weeks unless there are red flags

4 The use of a multidisciplinary and multimodal approach is essential to avoid diagnostic and management errors

5 Pain mechanisms must be considered when making a diagnostic classification to become a specific target of the therapeutic approach to control pain

6 LBP patients should be classified clinically as experiencing either nociceptive, neuropathic, mixed, or resulting in a central sensitization pain

7 In LBP, mechanisms of neuropathic pain include mechanical and inflammatory processes. In most cases, a complex interplay between these mechanisms is required to sustain the pain

8 Pain relief is the main target in LBP management

9 The goals of treatment for chronic LBP are to reduce pain, regain function, and prevent future exacerbations

10 Multidisciplinary and multimodal approaches represent the strategy to solve the problem of nonresponsive pain

11 NSAIDs and/or paracetamol represent the treatment of first choice in the pharmacological approach for the patient with LBP

12 In LBP with radiculopathy, corticosteroids are partially efficacious for pain control 
Table 1 continued

13 In moderate to severe unresponsive acute LBP, without recovery of function, opioid use is recommended in combination with NSAIDs and/ or paracetamol

14 Surgical treatment, including minimally invasive procedures, disk surgery, and spinal fusion should be used in selected patients

15 Combining opioids with other drugs has been shown to be more effective in managing pain than opioids alone

16 In chronic LBP, unresponsive to previous therapies, a multimodal approach is recommended, including strong opioids, myorelaxants, non-pharmacological therapies, and minimally invasive procedures

17 Antidepressants and anticonvulsants are recommended in patients with neuropathic pain for their analgesic properties

18 Early physical therapy following a new primary care consultation is associated with reduced risk of subsequent health care compared with delayed physical therapy

19 Multidisciplinary rehabilitation of patients with chronic LBP also includes educational and cognitive-behavioral approaches

The supporting bibliography for these statements can be found as supplementary material. $B M I$ body mass index, $L B P$ low back pain, NSAIDs nonsteroidal anti-inflammatory drugs

agree"; $4=$ "mostly agree"; or $5=$ "totally agree"). Survey statements addressed pain generators in LBP (S1, 5-7), individual risk factors (S2), LBP diagnosis (S3), and LBP treatment divided into the following categories: treatment goals (S8, 9), pharmacological (S11-13, 15, 17), non-pharmacological (S18, 19), surgical (S14), and multidisciplinary/multimodal (S4, 10, 16). Respondents were asked to express their degree of agreement or disagreement with each of the 19 statements and were subsequently invited to justify or explain their selection in an open comment section following each statement. Contact information for eligible physicians was extracted from a private national database; a survey invitation was sent via email, and the survey was accessed using a password-protected web link. Respondents were given a response deadline of 5 weeks from receipt of the survey.

\section{Ethical Statement}

The present study was not subject to approval by an ethical committee, as per national law and pertinent international guidelines. All survey responses were anonymized and handled via remote dispersed geographical participation.

\section{Statistical Analysis}

Anonymized survey responses were tabulated descriptively for the overall cohort and by physician specialty. Consensus was achieved when at least $70 \%$ of responses to a given statement were scored 3-5. Major consensus was determined when at least $99 \%$ of responses were scored 3-5. Open-ended responses were categorized thematically for each question by an independent observer. Descriptive statistical analyses were performed using STATA 14.1 software (StataCorp LLC, College Station, TX, USA).

\section{RESULTS}

\section{Respondent Characteristics}

A total of 121 physicians were invited to participate in the web survey. Of these, 89 (74\%) responded before the deadline. Respondents included 39 pain specialists (44\%), 16 physiatrists (18\%), 13 orthopedic surgeons $(15 \%), 11$ general practitioners (12\%), 4 occupational physicians $(4.5 \%), 3$ neurosurgeons/neurologists $(3.5 \%), 1$ rheumatologist $(1 \%), 1$ biotechnologist (1\%), and 1 gynecologist (1\%). 


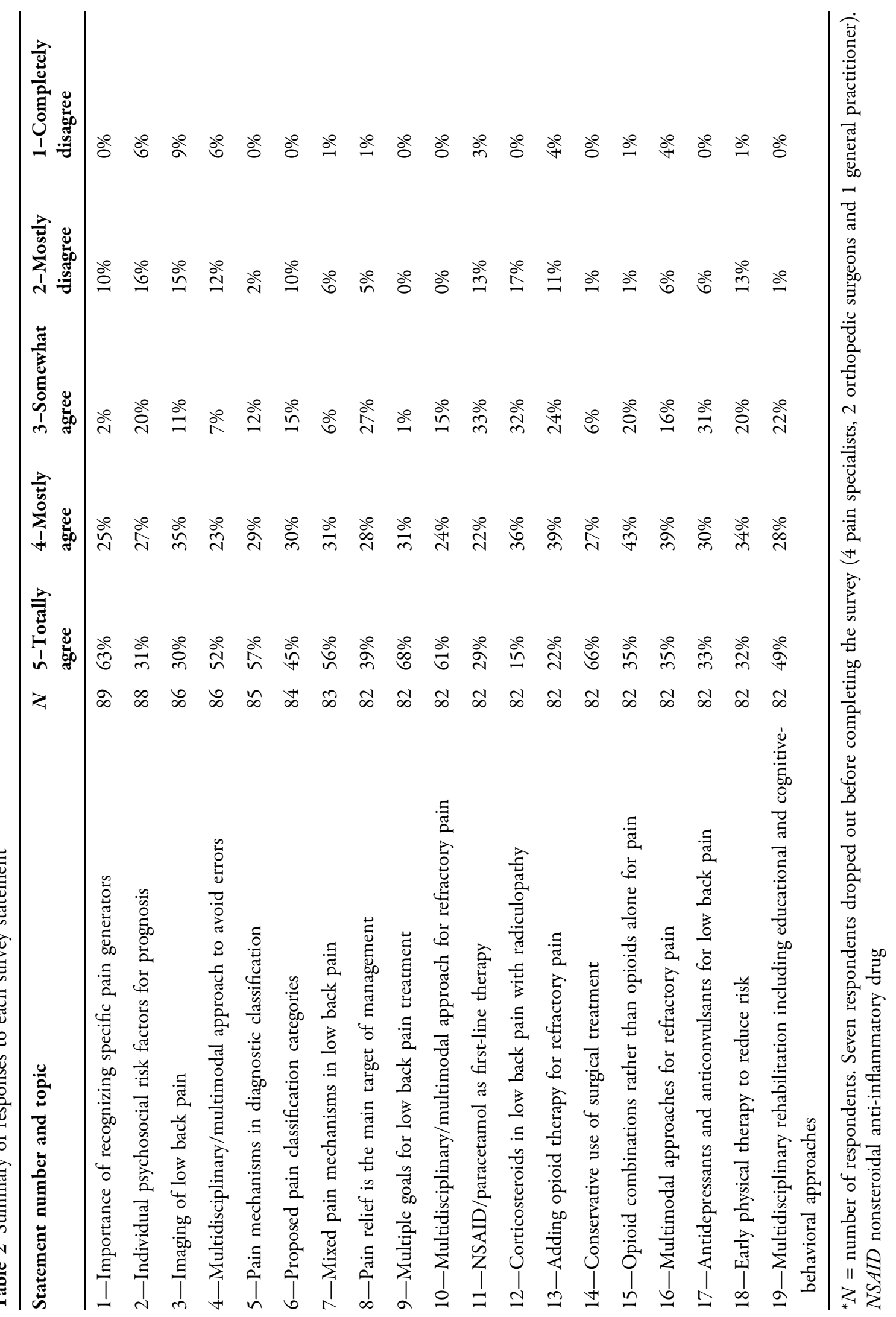




\section{Survey Consensus}

Consensus ( $\geq 70 \%$ scores $3-5$ ) was obtained for all 19 survey statements. The distributions of responses to each survey item are detailed in Table 2. Emergent themes in each statement category are summarized in Table 3.

\section{Pain Generators (S1, 5-7)}

In the pain generator category, the highest consensus was achieved for S5 (98\%): "Pain mechanisms must be considered when making a diagnostic classification to become a specific target of the therapeutic approach to control pain." Agreement was generally good for other statements in this category $(90 \%$ for S1 regarding the importance of recognizing pain generators for therapeutic targeting; 90\% for S6 regarding LBP mechanism-based classification; and $93 \%$ for $\mathrm{S} 7$ regarding the mechanistic nat-

Table 3 Summary trends in statement categories

\begin{tabular}{|c|c|c|}
\hline & $\begin{array}{l}\text { Disagree } \\
\text { mean }(S D)\end{array}$ & $\begin{array}{l}\text { Agree } \\
\text { mean } \\
(\mathrm{SD})\end{array}$ \\
\hline $\begin{array}{l}\text { Pain generators in LBP }(\mathbf{Q} \mathbf{1} \text {, } \\
\mathbf{5 - 7})\end{array}$ & $7 \%(4 \%)$ & $\begin{array}{l}93 \% \\
\quad(20 \%)\end{array}$ \\
\hline $\begin{array}{l}\text { Environmental and personal } \\
\text { factors (Q2) }\end{array}$ & $22 \%(-)$ & $78 \%(-)$ \\
\hline Diagnosis (Q3) & $24 \%(-)$ & $76 \%(-)$ \\
\hline Goals of treatment $(\mathbf{Q 8 , 9})$ & $3 \%(2 \%)$ & $\begin{array}{l}97 \% \\
\quad(22 \%)\end{array}$ \\
\hline $\begin{array}{l}\text { Pharmacological therapy } \\
\qquad(\mathbf{Q 1 1} \mathbf{1 3}, \mathbf{1 5}, \mathbf{1 7})\end{array}$ & $11 \%(2 \%)$ & $\begin{array}{l}89 \% \\
\quad(11 \%)\end{array}$ \\
\hline Surgical treatment $(\mathbf{Q 1 4})$ & $1 \%(-)$ & $99 \%(-)$ \\
\hline $\begin{array}{l}\text { Non-pharmacological therapy } \\
\qquad(\mathbf{Q 1 8}, \mathbf{1 9})\end{array}$ & $8 \%(6 \%)$ & $\begin{array}{l}92 \% \\
\quad(10 \%)\end{array}$ \\
\hline $\begin{array}{l}\text { Multimodal and } \\
\text { multidisciplinary approaches } \\
(\mathbf{Q} 4, \mathbf{1 0}, \mathbf{1 6})\end{array}$ & $9 \%(4 \%)$ & $\begin{array}{l}91 \% \\
\quad(18 \%)\end{array}$ \\
\hline
\end{tabular}

LBP low back pain, $S D$ standard deviation ure of neuropathic LBP). Comment responses to S1 frequently suggested that it is not always possible to identify the principal pain mechanism. In many cases, pain is driven by multiple mechanisms, and the tools in everyday clinical practice are often insufficient to distinguish classifications such as "central sensitization pain" (S6).

\section{Individual Risk Factors (S2)}

Although $78 \%$ of respondents agreed that individual and psychosocial risk factors influence the transition from acute to chronic LBP (Fig. 1), the response comments reflected discord regarding what those risk factors were (e.g., age, female sex). Other responses affirmed the importance of psychosocial factors for the subjective experience of pain.

\section{Diagnosis (S3)}

S3 was associated with the lowest degree of consensus in the whole survey (76\%). This statement addressed the use of imaging for LBP in the first 6 weeks after diagnosis in the absence of red flags. Some physicians stated that imaging was necessary to proceed with treatment or as a part of routine care; others indicated that 6 weeks was too long to wait and proposed shorter wait periods before imaging; and in one case a physician proposed extending the wait period to 8-12 weeks (Fig. 2).

\section{Treatment Goals $(S 8,9)$}

Agreement with S8 and S9 was high, at 94\% and $100 \%$ consensus, respectively. In qualitative responses, one emergent theme was that S8 ("Pain relief is the main target of LBP management") did not include other equally important goals such as activities of daily living/patient function, as expressed in S9. Accordingly, there was unanimous consensus that LBP management should equally weight pain relief, functional improvement, and future prevention (S9).

Pharmacological Approach (S11-13, 15, 17) Eighty-four percent of respondents agreed that NSAIDs/paracetamol are the first-choice pharmacological treatment in patients with LBP 


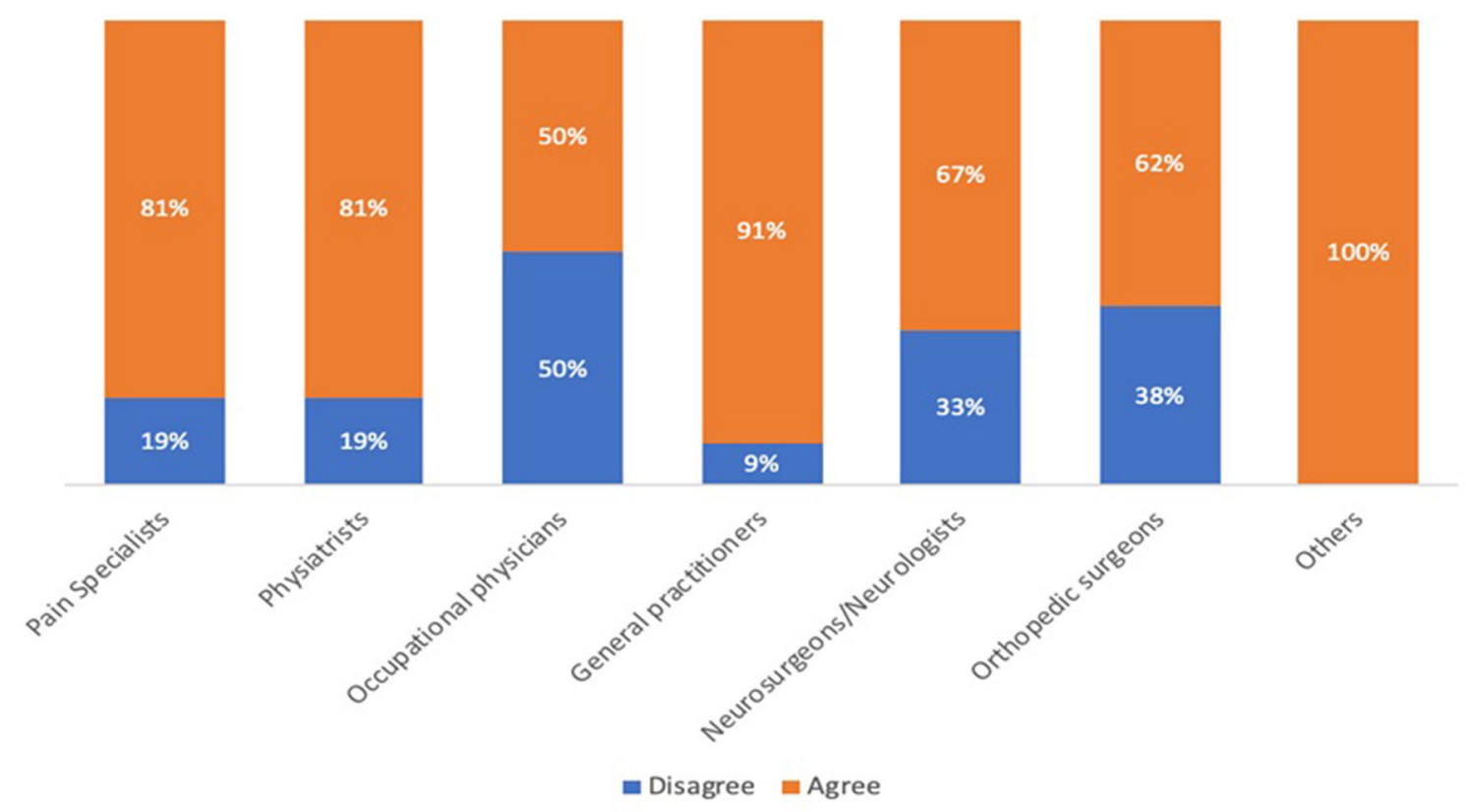

Fig. 1 S2: individual and psychosocial risk factors and the transition from acute to chronic LBP

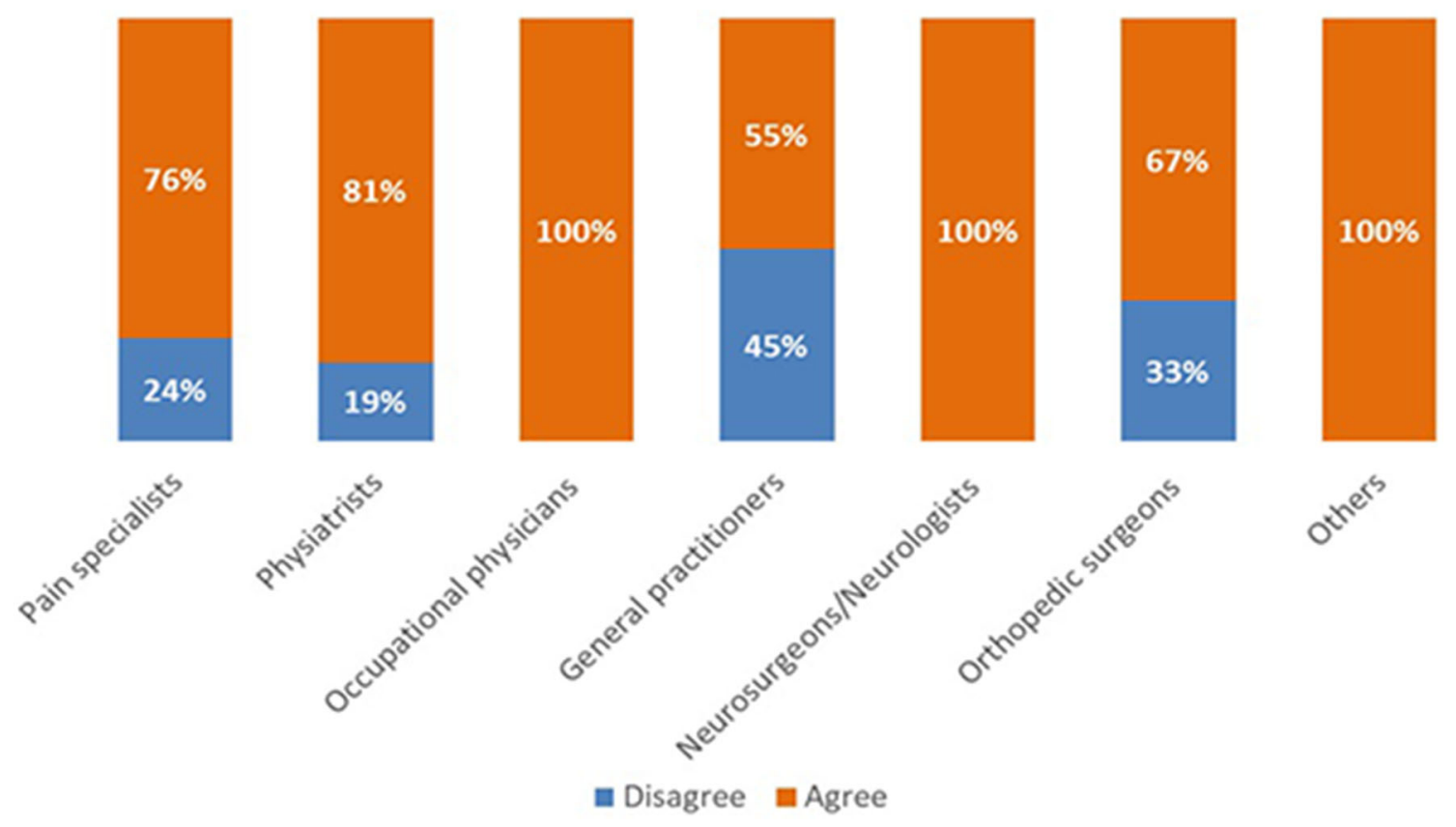

Fig. 2 S3: imaging is not recommended for LBP within the first 6 weeks unless there are red flags

(S11; Fig. 3). Respondents who disagreed with this statement qualified in their comments that the first-choice treatment depended on pain type/location and severity, and some highlighted the questionable efficacy of paracetamol for LBP in clinical studies. The highest degree of consensus in this category was achieved for S15 (98\%), which emphasized the superior efficacy of combining other pharmacological therapy with opioids as opposed to treatment with 


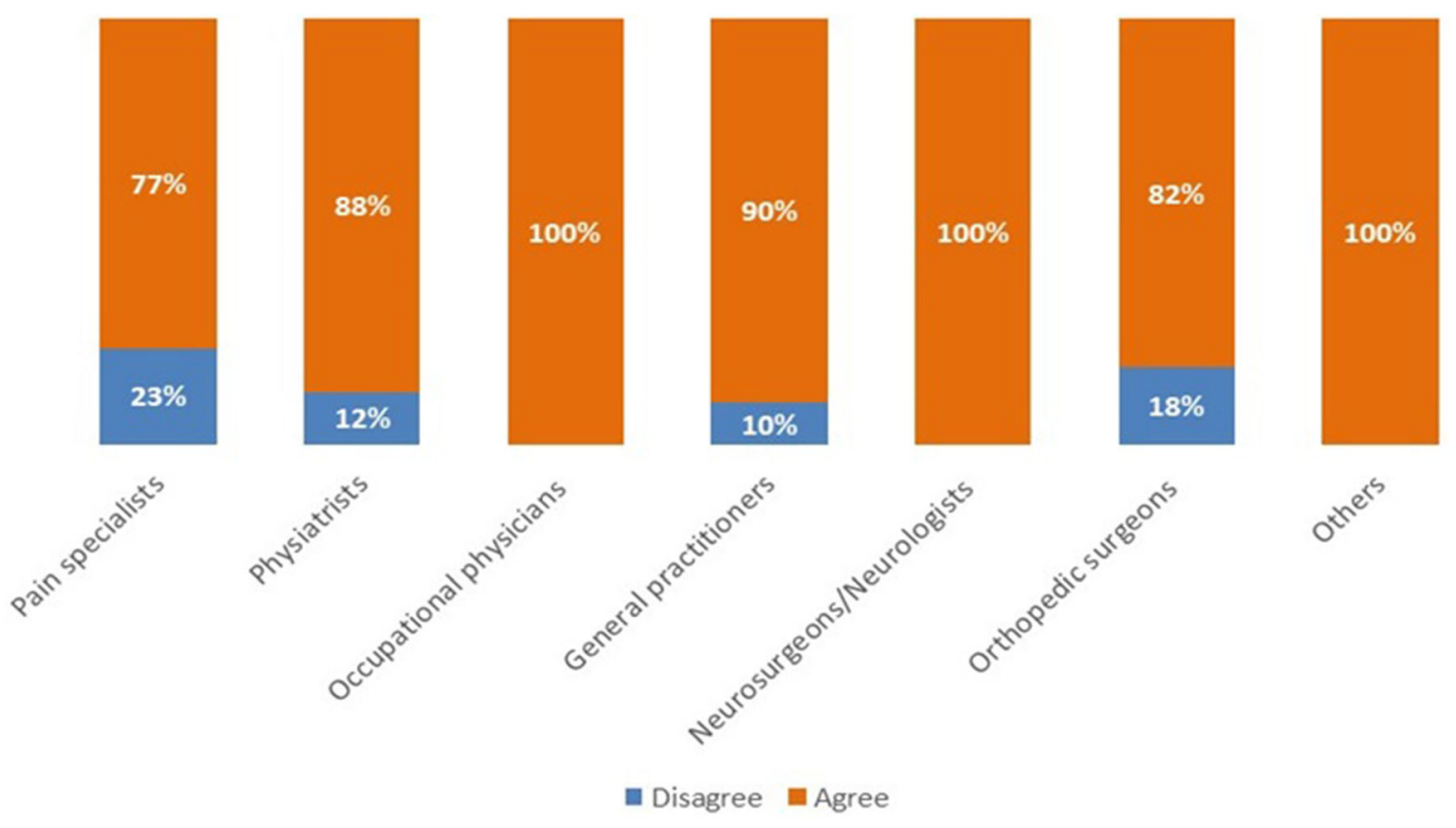

Fig. 3 S11: NSAIDs/paracetamol as first-line treatment for LBP

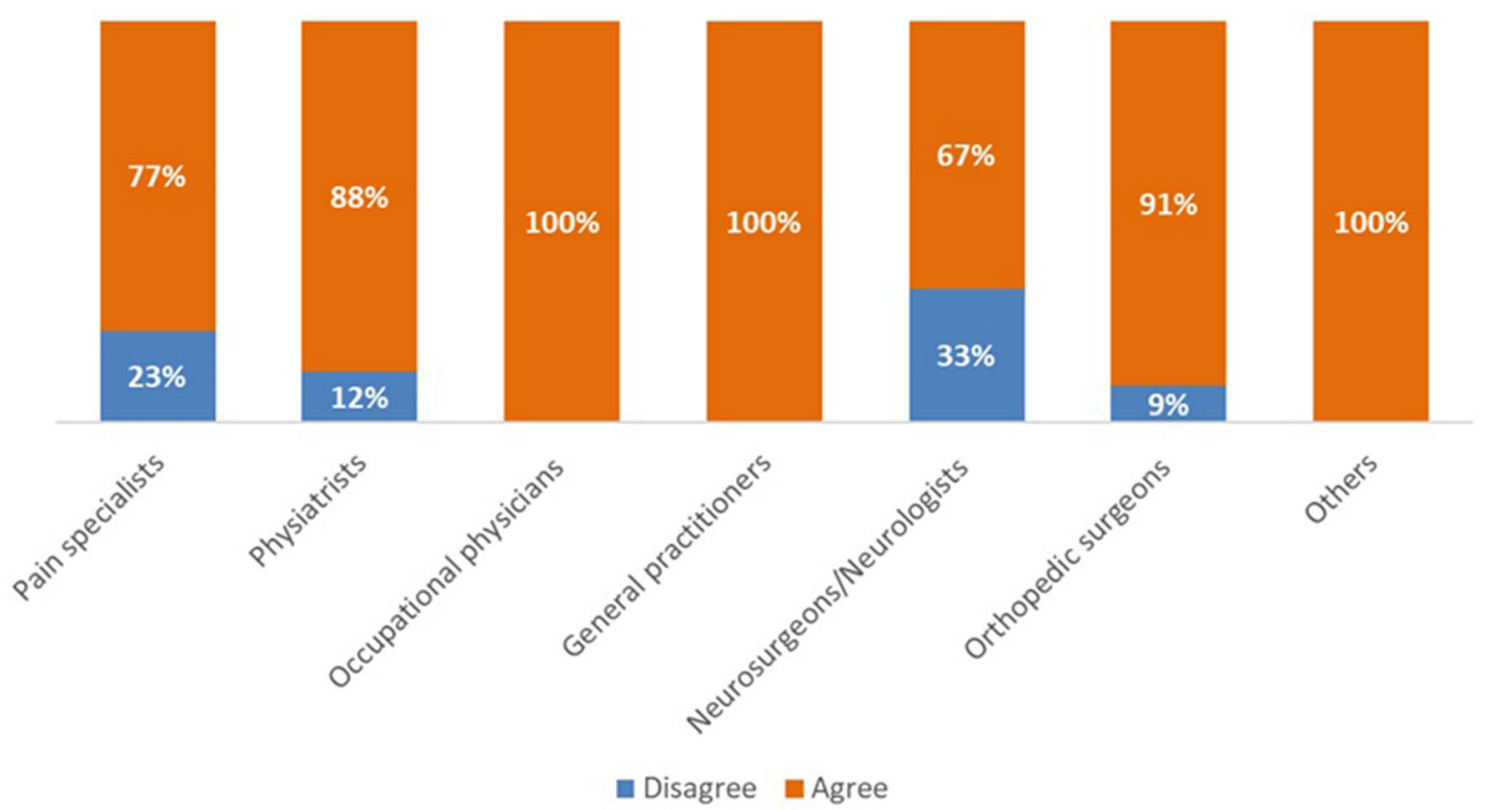

Fig. 4 S13: opioid use in combination with NSAIDs and/or paracetamol in moderate to severe unresponsive acute LBP

opioids alone in LBP. However, this pattern of responses did not represent general support of opioid use in LBP: in response to S13, 85\% of physicians agreed with the use of opioids in combination with NSAIDs/paracetamol in patients with moderate to severe refractory LBP.
In the comment responses, respondents noted that there was a low level of evidence for opioid use in chronic LBP and that opioids should be avoided, especially as long-term therapy, and only considered when all other therapies fail (Fig. 4). 
With regard to other pharmacological treatments, 83\% agreed with S12 about the use of corticosteroids in LBP with radiculopathy, and 94\% agreed with S17 about the use of antidepressants and anticonvulsants to treat neuropathic pain. Among respondents who disagreed with S12, a majority cited a lack of robust evidence for the efficacy of corticosteroids in LBP with radiculopathy and clinical observations that, at best, corticosteroids offered modest, short-lived efficacy if any at all.

\section{Non-Pharmacological Therapy $(S 18,19)$}

Eighty-six percent of respondents affirmed that early physical therapy was useful for reducing the risk of needing subsequent health care in patients with LBP (S18). Respondents who disagreed with this statement argued that the utility of physical therapy depended on the origin and type of pain. Some stated that physical therapy was not necessarily indicated in the acute phase of injury and could actually worsen the problem in some cases, whereas others argued that there was poor evidence for the utility of physical therapy in the rehabilitative phase (although 1 respondent noted that available guidelines recommend physical therapy in chronic LBP). Above all else, there was a general lack of consensus regarding what was meant by "physical therapy": there were mentions of physical rehabilitation, physical exercise, "soft" activities, and physio-kinesitherapy.

In contrast, $99 \%$ of respondents agreed about the inclusion of educational and cognitive-behavioral approaches in the multidisciplinary management of LBP (S19), even if there was some ambiguity about how these approaches could be implemented in a routine clinical setting.

\section{Surgical (S14)}

There was 99\% agreement regarding S14, which recommended the targeted use of surgical procedures including minimally invasive procedures, disk surgery, and spinal decompression and/or fusion to treat LBP ("in selected patients").

\section{Multimodal and Multidisciplinary Approach \\ $(S 4,10,16)$}

S16 regarded multimodal treatment (e.g., multiple pharmacological, non-pharmacological, and interventional approaches) of chronic LBP and made specific mention of strong opioids and minimally invasive surgical treatment. Although $90 \%$ of respondents agreed with the statement, those who disagreed asserted a poor level of evidence for strong opioids in LBP and the need to use minimally invasive procedures in a targeted manner (i.e., only where expressly indicated). Some of these ideas were echoed in the responses to $\mathrm{S} 4$, which stated that a multimodal/multidisciplinary approach was necessary to avoid diagnostic and management errors (82\% consensus). Respondents asserted that a multimodal or multidisciplinary approach can be useful but is not always indicated, emphasizing the impracticality of applying a multidisciplinary/multimodal approach in all cases of LBP. In the comments section, respondents expressed that these approaches were more logical in cases of persistent pain refractory to conventional therapeutic or unimodal approaches. Consistent with this sentiment, there was $100 \%$ consensus with the statement, "Multidisciplinary and multimodal approaches represent the strategy to solve the problem of nonresponsive pain" (S10).

\section{DISCUSSION}

This study generated a series of 19 statements regarding appropriate practices for the realworld clinical diagnosis and management of LBP. Literature-supported statements were derived from the consensus of an expert panel and subsequently validated by survey in a larger sample of physicians with various specialties. Given the highly heterogeneous nature of LBP, statement feedback often advised tailoring care on an individual basis, for example depending on the duration of a patient's symptoms, type and origin of LBP, and individual patient characteristics. Physicians were generally in favor of a multidisciplinary approach, but often expressed ambiguity regarding the feasibility of 
multidisciplinary management strategies in routine clinical care.

\section{Pain Generators}

Major consensus was achieved regarding the importance of making a diagnostic classification and identifying targets of therapy (S1 and S5, respectively), consistent with the proposed ACTTION-APS Pain Taxonomy (AAPT) [14] for classifying pain, which includes pain mechanism as one of the five dimensions that must be considered when making a diagnostic classification. Yet, the response comments to S1 and S5 reflected discord about mechanism categories and the feasibility of making these distinctions in a clinical setting. LBP is a highly heterogeneous disorder that can result from a variety or combination of pathological causes. A previous Delphi survey study categorized LBP pain types as either predominantly nociceptive, neuropathic, or central sensitization pain [15]. While respondents in our survey agreed that LBP can be classified clinically as nociceptive, neuropathic, central sensitization pain, or mixed (S6), respondents qualified in the comment responses that they did not necessarily agree with including central sensitization pain as a category, saying that it was too broad and often a contributing factor in many pain states. Given the frequently mixed nature of pain in patients with LBP, and to improve the feasibility of pain classification in a real-world context, physicians should select a category that reflects the most prominent characteristics of a patient's pain and use this category to guide subsequent treatment decisions.

\section{Diagnosis}

The correct diagnosis of LBP should include a thorough history with screening for early redflag symptoms and a general physical examination. In some cases, local anesthetic blocks and responses to initial treatment can provide valuable information that can contribute to a more specific diagnosis while respecting ethical considerations and providing pain relief. In the event that a patient presents with severe or progressive neurological deficits or when serious underlying conditions are suspected, other diagnostic modalities including lumbar radiography, magnetic resonance imaging (MRI), computed axial tomography (CT), and electromyography may be indicated. In our survey, the statement yielding the lowest degree of consensus was, “Imaging isn't recommended for LBP within the first 6 weeks unless there are red flags" (S3), and this poor agreement among physicians was also reflected in comment responses. Of note, general practitioners and orthopedic surgeons were the most likely to disagree with S3 and advocated early imaging, probably because imaging in the early stage of diagnosis is used to guide specialist referral and determine the necessity of orthopedic intervention, respectively. The American College of Radiology does not recommend LBP imaging within the first 6 weeks unless there are red flags [5]. In contrast, the National Institute for Health and Care Excellence (NICE) guidelines [16] advise against routine imaging in a nonspecialist setting for people with LBP, with or without sciatica, and only support imaging in specialist settings of care for people with LBP with or without sciatica if the result is likely to change treatment. The British Pain Society also recommends that only clinicians able to interpret the resulting images should make requests for MRI for radicular symptoms [17]. In general, MRI is too sensitive and not specific enough to allow screening for onward referral and is therefore not cost-effective in LBP. In studies of degenerative lumbar stenosis, MRI abnormalities correlate poorly with symptoms and can be detected in $20-67 \%$ of asymptomatic patients $[18,19]$. Similar ambiguity has been reported for facet joint pain.

\section{Treatment}

\section{Treatment Goals}

Unanimous consensus was obtained regarding the statement, "The goals of treatment of chronic LBP are to reduce pain, regain function, and prevent future exacerbations" (S9), whereas less definitive agreement was obtained for the statement, "Pain relief is the main target in LBP 
management" (S8). Those who disagreed with the latter statement cited the importance of function or activities of daily living in patients with LBP. These results parallel a field-wide shift away from the traditional perspective of pain as a nuisance symptom and towards viewing LBP as a comprehensive syndrome that requires management in-kind [5, 6, 15, 20-29].

\section{Pharmacological Management of LBP}

Different guidelines are available for the pharmacological treatment of acute and subacute LBP [6]. Pharmacological management generally utilizes paracetamol and NSAIDs as first-line treatment for most patients. Indeed, the use of anti-inflammatory agents has emerged as important [30], as well as opioids, tricyclic antidepressants, and anticonvulsants, depending on the type of LBP and patient history. Ibuprofen has long been touted as a mainstay of LBP management [31]. A recent Delphi study has focused the attention of clinicians on the use of multimodal analgesia for moderate to severe acute pain in the case of LBP as well [32]. Muscle relaxants are also commonly employed as second-line therapy in patients with refractory pain.

An important theme arising from the comment responses was that the first-choice therapy for LBP often depends on the severity of presenting pain and the origin of pain. After the failure of first-line therapy with NSAIDs and/or paracetamol, some guidelines recommend a short cycle of opioids [6], whereas the NICE guideline advises against opioid use entirely [16]. In our survey, most respondents agreed that the use of a combination opioid and NSAID/paracetamol was appropriate in moderate to severe acute refractory LBP, but qualified that opioid therapy should never be offered as first-line therapy, especially because opioids do not necessarily work on the pain generator. Rather, respondents favored the use of nonopioid options such as muscle relaxants, nonpharmacological therapy, and minimally invasive surgery (when indicated) in a multimodal approach to refractory pain [33]. Clinicians should only consider prescribing a short-term opioid, even in multimodal combination with paracetamol or a NSAID [34], if the potential benefits outweigh the risks for individual patients, and only after a realistic discussion of possible risks and benefits [6].

Corticosteroids are controversially indicated in some instances of LBP [26, 35-37]. In LBP with radiculopathy, corticosteroids are commonly added for pain control despite a previous study demonstrating a modest improvement in function but no improvement in pain after a short course of oral steroids among patients with acute radiculopathy due to a herniated lumbar disk [35]. In our survey, most respondents agreed that corticosteroids have partial efficacy in acute radiculopathy. Justifications offered by respondents reaffirmed that corticosteroids are not always effective, especially as monotherapy, but are used frequently and inappropriately in LBP. Respondents also indicated that they had difficulty justifying the use of corticosteroids for radicular pain in the absence of supporting literature.

Despite consensus in response to S17 regarding the use of antidepressants and anticonvulsants for the management of neuropathic pain, the main reasons for disagreement were that the onset of pain relief, while moderate, can take several weeks, and furthermore that these agents can be associated with several unpleasant or intolerable side effects. There are clear indications for these medications in pure neuropathic pain [38]; however, literature evidence for the use of anticonvulsants in LBP, with or without a neuropathic component, is less robust $[39,40]$. Unfortunately, the reliability of available studies is questionable given a notoriously high rate of false-negative findings in trials for neuropathic pain [41] and in light of widespread clinician preference for these medications in chronic LBP. Anticonvulsants and antidepressants are among the most highly sold pharmacological agents for chronic pain. Accordingly, physicians should consider these medicines in cases where a neuropathic pain generator is thought to account for a majority of LBP symptoms [24, 42, 43].

\section{Non-Pharmacological Approaches to LBP}

Non-pharmacological approaches to LBP typically include acupuncture, spinal manipulation, psychotherapy, and others [6]. The American 
College of Physicians (ACP) published a 2017 guideline that utilized the ACP grading system to generate a systematic review of randomized controlled trials published through April 2015 on noninvasive pharmacological and nonpharmacological treatments for LBP [6]. Nonpharmacological treatments were strongly recommended as first line in patients with chronic LBP, with proposed options including exercise, multidisciplinary rehabilitation, acupuncture, mindfulness-based stress reduction, tai-chi, yoga, motor control exercises, progressive relaxation, electromyography biofeedback, lowlevel laser therapy, operant therapy, cognitivebehavioral therapy, and spinal manipulation. A recent systematic review provided a useful overview of these options in a context of chronic LBP [44]. Unfortunately, most nonpharmacological therapies for chronic LBP are associated with small to moderate and usually short-term effects on pain [45]. In our survey, S18 addressed an association between early physical therapy following a new primary care consultation and risk reduction for subsequent health care. This statement achieved major consensus but with varying degrees of agreement, possibly due to the absence of a shared guideline defining a common and clear interpretation of the term "physical therapy." Respondents specifically disagreed about the use of physical therapy in the acute phase of LBP and in patients with high-intensity pain, suggesting that the benefits of early physical therapy are unclear and depend on the type of LBP. In some cases, immediate pharmacological therapy that provides some degree of pain relief can improve the feasibility and efficacy of early physical therapy.

Respondents were in almost unanimous agreement about the utility of educational and cognitive-behavioral interventions as part of an effective multidisciplinary approach in chronic LBP (S19). Cognitive-behavioral approaches target both physical and psychosocial symptoms related to pain, help patients develop coping skills, and augment the outcome benefits associated with physical therapy [46]. Unfortunately, there are significant barriers to adopting cognitive-behavioral approaches in clinical practice due to feasibility and time constraints. Moreover, cognitive-behavioral methods, in general, are not reimbursed by the national health systems. This may partly explain noncompliance with recommendations for the use of cognitive-behavioral interventions in clinical practice [46].

\section{Surgical (Orthopedic) Intervention}

Current guideline recommendations advise surgical (orthopedic) treatment only in cases of chronic LBP refractory to pharmacotherapy or other management. In some cases, procedures such as spinal decompression, spinal fusion, and arthroplasty may be necessary [47]. In our survey, almost all respondents agreed that surgical treatment, including minimally invasive procedures, should only be recommended in patients with specific indications (S14). Importantly, structural changes on imaging alone are not necessarily an indication for surgery: only a small proportion of patients with structural changes have pain related to these changes [48]. Accordingly, physicians should opt for surgical intervention only when a given structural change in the spine is confirmed to be a chief pain generator in the patient.

\section{Multidisciplinary Treatment}

Survey respondents unanimously agreed that multidisciplinary (and multimodal) treatment approaches were a solution for nonresponsive pain (S10). However, physicians felt that not all cases of LBP require multidisciplinary management, and that implementing these comprehensive strategies in all patients is not feasible or a wise use of resources. This sentiment partly contrasts with guidelines for chronic LBP, which emphasize the utility of multidisciplinary rehabilitation and complementary strategies like acupuncture and exercise for pain management [45].

\section{Limitations}

While this study provides a unique insight into the state of LBP management using a modified Delphi approach, there were some limitations. Given the nature of the consensus statements, we excluded specialists who treat LBP but are 
unable to prescribe pharmacological therapy (e.g., physiotherapists, psychologists) and would therefore have responded based on secondhand knowledge in many cases. Our survey also excluded other physicians such as psychiatrists who play an important role in managing the affective component of chronic pain, but are not responsible for the diagnosis of LBP or certain modalities of pharmacological treatment (e.g., prescription of opioids, surgical intervention). Second, our thematic analysis of the survey comments may have over- or underrepresented certain sentiments among LBP practitioners. Third, in view of very recent data on possible markers of LBP $[46,49]$, there will be a potential revision on the diagnostic approach. Future efforts might include a content analysis designed to detect geographical differences in clinical practice and perceptions. It is our hope that increased awareness about trends in current clinical practice versus the recommendations of evidence-based guidelines will facilitate the evolution of LBP management.

\section{CONCLUSIONS}

The results of this study yield a list of consensus statements that reflect real-world physician experience and preferences for the diagnosis and management of LBP. The most prominent theme emerging from survey responses was a strong agreement with the use of multidisciplinary-multimodal approaches to provide comprehensive therapy that not only addresses pain, but also improves function and acts on pain generator mechanisms to decrease the likelihood of recurrence. In a clinical context, this theme favors a tailored, "personalized medicine" approach to pain management that utilizes all available pharmacological tools and other multidisciplinary methods to manage individual patients based on pain intensity, pain characteristics, specific pain generators, function, and quality of life.

\section{ACKNOWLEDGEMENTS}

The authors graciously thank the survey respondents for their participation, namely Rosanna Accardo; Gioacchino Altomano; Francesco Amato; Ezio Amorizzo; Marika Aprea; Roberto Arcioni; Caterina Aurilio; Manlio Barbarisi; Giovanni Bardanti Brodano; Antonio Barrucci; Pedro Berjano; Marzio Bevilacqua; Massimiliano Bianco; Ilaria Bologna; Cristiano Bonacci; Lucio Bucci; Dario Calafiore; Marco Cascella; Maria Luigina Chiarinelli; Pasquale Cinella; Umberto Colella; Leonardo Consoletti; Silvio Crinò; Marco Crostelli; Claudio Curci; Paolo De Blasiis; Federico De Iure; Pasquale De Negri; Alessandro De Sire; Paolo D'Ermenegildo; Massimiliano Di Filippo; Silvia Di Lorenzo; Rossella Di Rauso; Mario Di Silvestre; Carlo Doria; Carmen Drammis; Clelia Esposito; Marco Fiore; Laura Frizzi; Giosuè Gargiulo; Teresa Gianmattei; Sandro Giansante; Fabio Iannotti; Mario Iannotti; Fabrizio La Mura; Roberto Latina; Maria Teresa Lattanzio; Sara Liguori; Alessandro Lupo; Nicola Luxardo; Paolo Marchettini; Marco Maresca; Ida Marsili; Roberta Martinelli; Giuseppe Maso; Leo Massari; Maurizio Massetti; Marco Mattucci-Cernic; Daniele Mauro; Fabrizio Micheli; Antimo Moretti; Luigi Nardi; Antonella Paladini; Antonio Palagiano; Marco Paoletta; Francesco Paoletti; Mario Pasqualone; Lorenzo Pasquariello; Maria Beatrice Passavanti; Andrea Piazzolla; Alba Piroli; Gloria Piscina; Vincenzo Pota; Filomena Puntillo; Roberta Ricci; Riccardo Rinaldi; Giuseppe Rinonapoli; Pasquale Sansone; Daniela Santarelli; Francesco Scandone; Paolo Scarsella; Vittorio Schweiger; Francesco Ciro Tamburelli; Stefano Tamburin. Their support was essential to obtain balanced results.

Funding. Sponsorship for this study and the Rapid Service Fee were funded by Angelini S.P.A.

Medical Writing and/or Editorial Assistance. Draft preparation and editorial assistance for this article were funded by Sanitanova and were provided by Claudia Laterza, MD, of 
Sanitanova S.r.l. and Ashley Symons, $\mathrm{PhD}$ (freelance medical writer).

Authorship. All named authors meet the International Committee of Medical Journal Editors (ICMJE) criteria for authorship for this article, take responsibility for the integrity of the work as a whole, and have given their approval for this version to be published.

Disclosures. Giustino Varrassi is consultant for Abbott, Angelini, Dompé, Grünenthal, Malesci, Menarini, Molteni, Pfizer, Shonogi, and Takeda. He has received research grants from Dompé, the Fondazione Internazionale Maugeri, and the Consiglio Nazionale per la Ricerca. He also serves on the Editorial Board of several scientific journals. Giustino Varrassi is also is the Editor-in-Chief of this journal. Biagio Moretti, Maria Caterina Pace, Paolo Evangelista, and Giovanni Iolascon have no conflicts of interest to disclose.

Compliance with Ethics Guidelines. This article does not contain any studies with human participants or animals performed by any of the authors. Ethics committee approval is not required for this anonymous survey. All clinicians indicated their willingness to voluntarily take part in the study. This survey was completely voluntary, and anyone had the right to terminate their participation at any time without penalty. The participation in this research was completely anonymous to the researchers. Any results that are reported will only be presented in the aggregate across all survey respondents.

Data Availability. The data sets generated and/or analyzed during the current study are available from the corresponding author on reasonable request.

Open Access. This article is licensed under a Creative Commons Attribution-NonCommercial 4.0 International License, which permits any non-commercial use, sharing, adaptation, distribution and reproduction in any medium or format, as long as you give appropriate credit to the original author(s) and the source, provide a link to the Creative Commons licence, and indicate if changes were made. The images or other third party material in this article are included in the article's Creative Commons licence, unless indicated otherwise in a credit line to the material. If material is not included in the article's Creative Commons licence and your intended use is not permitted by statutory regulation or exceeds the permitted use, you will need to obtain permission directly from the copyright holder. To view a copy of this licence, visit http://creativecommons.org/licenses/by$\mathrm{nc} / 4.0 /$.

\section{REFERENCES}

1. Koes BW, van Tulder MW, Thomas S. Diagnosis and treatment of low back pain. BMJ. 2006;332:1430-4. https://doi.org/10.1136/bmj.332.7555.1430.

2. Hayden J, van Tulder MW, Malmivaara A, Koes BW. Exercise therapy for treatment of non-specific low back pain. Cochrane Database Syst Rev. 2005. https://doi.org/10.1002/14651858.CD000335. pub2.

3. Varrassi G, Fusco M, Coaccioli S, Paladini A. Chronic pain and neurodegenerative processes in elderly people. Pain Pract. 2015;15:1-3. https://doi. org/10.1111/papr.12254.

4. Tarantino U, Iolascon G, Cianferotti L, Masi L, Marcucci G, Giusti F, et al. Clinical guidelines for the prevention and treatment of osteoporosis: summary statements and recommendations from the Italian Society for Orthopaedics and Traumatology. J Orthop Traumatol. 2017;18:3-36. https:// doi.org/10.1007/s10195-017-0474-.

5. Patel ND, Broderick DF, Burns J, Deshmukh TK, Fries IB, Harvey HB, et al. ACR appropriateness criteria low back pain. J Am Coll Radiol. 2016;13: 1069-78. https://doi.org/10.1016/j.jacr.2016.06. 008.

6. Qaseem A, Wilt TJ, McLean RM, Forciea MA. Noninvasive treatments for acute, subacute, and chronic low back pain: a clinical practice guideline from the American College of Physicians. Ann Intern Med. 2017;166:514-30. https://doi.org/10. 7326/M16-2367.

7. Paladini A, Varrassi G, Bentivegna G, Carletti S, Piroli A, Coaccioli S. Palmitoylethanolamide in the treatment of failed back surgery syndrome. Pain Res 
Treat. 2017;1:1-6. https://doi.org/10.1155/2017/ 1486010.

8. Ehrlich GE. Low back pain-World Health Organization. Bull World Health Organ. 2003;81:671-6. https://doi.org/10.1016/B0-44-306557-8/50228-8.

9. Pergolizzi JV, Paladini A, Varrassi G, Raffa RB. Change pain: ever evolving-an update for 2016 . Pain Ther. 2016;5:127-33. https://doi.org/10.1007/ s40122-016-0058-X.

10. Amonkar SJ, Dunbar AM. Do patients and general practitioners have different perceptions about the management of simple mechanical back pain? Int Musculoskelet Med. 2011;33:3-7. https://doi.org/ 10.1179/175361511X12972993698186.

11. Ramanathan SA, Hibbert PD, Maher CG, Day RO, Hindmarsh DM, Hooper TD, et al. CareTrack: toward appropriate care for low back pain. Spine (Phila Pa 1976). 2017;42:E802-9. https://doi.org/10. 1097/BRS.0000000000001972.

12. Hsu CC, Sandford BA. The Delphi technique: making sense of consensus. Pract Assess Res Eval. 2007;12:1-8.

13. Taylor E. We agree, don't we? The Delphi method for health environments research. HERD Heal Environ Res Des J. 2020;13:11-23. https://doi.org/ $10.1177 / 1937586719887709$.

14. Fillingim RB, Bruehl S, Dworkin RH, Dworkin SF, Loeser JD, Turk DC, et al. The ACTTION-American Pain Society Pain Taxonomy (AAPT): an evidencebased and multidimensional approach to classifying chronic pain conditions. J Pain. 2014;15:241-9. https://doi.org/10.1016/j.jpain.2014.01.004.

15. Nijs J, Apeldoorn A, Hallegraeff H, Clark J, Smeets R, Malfliet A, et al. Low back pain: guidelines for the clinical classification of predominant neuropathic, nociceptive, or central sensitization pain. Pain Phys. 2015;18:E333-46.

16. Bernstein IA, Malik Q, Carville S, Ward S. Low back pain and sciatica: summary of NICE guidance. BMJ. 2017. https://doi.org/10.1136/bmj.i6748.

17. Lee J, Gupta S, Price C, Baranowski AP. Low back and radicular pain: a pathway for care developed by the British Pain Society. Br J Anaesth. 2013. https:// doi.org/10.1093/bja/aet172.

18. Zylbersztejn S, de Spinelli LF, Rodrigues NR, Werlang PM, Kisaki Y, Rios ARM, et al. Degenerative stenosis of the lumbar spine. Rev Bras Ortop (English Ed). 2012;47:286-91. https://doi.org/10.1016/ S2255-4971(15)30100-2.
19. Jarvik JG, Deyo RA. Diagnostic evaluation of low back pain with emphasis on imaging. Ann Intern Med. 2002;137:586. https://doi.org/10.7326/00034819-137-7-200210010-00010.

20. Ronzi Y, Roche-Leboucher G, Bègue C, Dubus V, Bontoux L, Roquelaure Y, et al. Efficiency of three treatment strategies on occupational and quality of life impairments for chronic low back pain patients: is the multidisciplinary approach the key feature to success? Clin Rehabil. 2017;31:1364-73. https:// doi.org/10.1177/0269215517691086.

21. Pinto RZ, Maher CG, Ferreira ML, Ferreira PH, Hancock M, Oliveira VC, et al. Drugs for relief of pain in patients with sciatica: systematic review and meta-analysis. BMJ. 2012;344:e497. https://doi.org/ 10.1136/bmj.e497.

22. Gilmore CA, Kapural L, McGee MJ, Boggs JW. Percutaneous peripheral nerve stimulation (PNS) for the treatment of chronic low back pain provides sustained relief. Neuromodulation. 2019;22: 615-20. https://doi.org/10.1111/ner.12854.

23. Rivera CE. Lumbar epidural steroid injections. Phys Med Rehabil Clin N Am. 2018;29:73-92. https:// doi.org/10.1016/j.pmr.2017.08.007.

24. Gouveia N, Rodrigues A, Ramiro S, Eusébio M, Machado PM, Canhão $\mathrm{H}$, et al. The use of analgesic and other pain-relief drugs to manage chronic low back pain: results from a national survey. Pain Pract. 2017;17:353-65. https://doi.org/10.1111/ papr. 12455.

25. Miller SM. Low back pain: pharmacologic management. Prim Care. 2012;39:499-510. https://doi.org/ 10.1016/j.pop.2012.06.005.

26. Chou R, Deyo R, Friedly J, Skelly A, Weimer M, Fu $\mathrm{R}$, et al. Systemic pharmacologic therapies for low back pain: a systematic review for an american college of physicians clinical practice guideline. Ann Intern Med. 2017;166:480-92. https://doi.org/ 10.7326/M16-2458.

27. Madson TJ. Considerations in physical therapy management of a non-responding patient with low back pain. Physiother Theory Pract. 2017;33: 743-50. https://doi.org/10.1080/09593985.2017. 1331480 .

28. Cruccu G, Truini A. Tools for assessing neuropathic pain. PLoS Med. 2009;6:e1000045. https://doi.org/ 10.1371/journal.pmed.1000045.

29. Bardin LD, King P, Maher CG. Diagnostic triage for low back pain: a practical approach for primary care. Med J Aust. 2017;206:268-73. https://doi.org/ $10.5694 / \mathrm{mja} 16.00828$. 
30. Varrassi G, Alon E, Bagnasco M, Lanata L, MayoralRojals V, Paladini A, et al. Towards an effective and safe treatment of inflammatory pain: a Delphi-guided expert consensus. Adv Ther. 2019;36:2618-37. https://doi.org/10.1007/s12325-019-01053-x.

31. Varrassi G, Pergolizzi JV, Dowling P, Paladini A. Ibuprofen safety at the golden anniversary: are all NSAIDs the same? A Narrative Review. Adv Ther. 2020;37:61-82. https://doi.org/10.1007/s12325019-01144-9.

32. Varrassi G, Coaccioli S, De-Andrés J, Hanna M, Macheras G, Montero A, et al. Expert consensus on clinical use of an orally administered Dexketoprofen plus tramadol fixed-dose combination in moderate-to-severe acute pain: a Delphi study. Adv Ther. 2019. https://doi.org/10.1007/s12325-01901096-0.

33. Meloncelli S, Germani G, Urti I, Divizia M, Rosciano M, Puntillo F, Paladini A, Varrassi G. Endoscopic radiofrequency facet joint treatment in patients with low back pain: technique and long term results. A prospective cohort study. Ther Adv Muscul Dis. 2020. https://doi.org/10.1177/ $1759720 X 20958979$.

34. Varrassi G, Yeam CT, Rekatsina M, Pergolizzi JV, Zis $\mathrm{P}$, Paladini A. The expanding role of the COX inhibitor/opioid receptor agonist combination in the management of pain. Drugs. 2020. https://doi. org/10.1007/s40265-020-01369-x.

35. Goldberg H, Firtch W, Tyburski M, Pressman A, Ackerson L, Hamilton L, et al. Oral steroids for acute radiculopathy due to a herniated lumbar disk: a randomized clinical trial. JAMA. 2015;313:1915-23. https://doi.org/10.1001/jama.2015.4468.

36. Schilling LS, Markman JD. Corticosteroids for pain of spinal origin: epidural and intraarticular administration. Rheum Dis Clin North Am. 2016;42(137-55):ix. https://doi.org/10.1016/j.rdc. 2015.08.003.

37. Mehta P, Syrop I, Singh JR, Kirschner J. Systematic review of the efficacy of particulate versus nonparticulate corticosteroids in epidural injections. PM R. 2017;9:502-12. https://doi.org/10.1016/j.pmrj. 2016.11.008.

38. Finnerup NB, Attal N, Haroutounian S, McNicol E, Baron R, Dworkin RH, et al. Pharmacotherapy for neuropathic pain in adults: a systematic review and meta-analysis. Lancet Neurol. 2015;14:162-73. https://doi.org/10.1016/S1474-4422(14)70251-0.

39. Mathieson S, Maher CG, McLachlan AJ, Latimer J, Koes BW, Hancock MJ, et al. Trial of pregabalin for acute and chronic sciatica. N Engl J Med. 2017;376: 1111-20. https://doi.org/10.1056/NEJMoa1614292.
40. Enke O, New HA, New CH, Mathieson S, McLachlan AJ, Latimer J, et al. Anticonvulsants in the treatment of low back pain and lumbar radicular pain: a systematic review and meta-analysis. Can Med Assoc J. 2018;190:E786-93. https://doi.org/10. 1503/cmaj.171333.

41. Treister R, Lawal OD, Shecter JD, Khurana N, Bothmer J, Field $\mathrm{M}$, et al. Accurate pain reporting training diminishes the placebo response: results from a randomised, double-blind, crossover trial. PLoS ONE. 2018;13:e0197844. https://doi.org/10. 1371/journal.pone.0197844.

42. Koes BW, Backes D, Bindels PJE. Pharmacotherapy for chronic non-specific low back pain: current and future options. Expert Opin Pharmacother. 2018;19:537-45. https://doi.org/10.1080/ 14656566.2018.1454430.

43. Yan Y-Y, Li C-Y, Zhou L, Ao L-Y, Fang W-R, Li Y-M. Research progress of mechanisms and drug therapy for neuropathic pain. Life Sci. 2017;190:68-77. https://doi.org/10.1016/j.lfs.2017.09.033.

44. Vitoula K, Venneri A, Varrassi G, Paladini A, Sykioti $\mathrm{P}$, Adewusi J, et al. Behavioral therapy approaches for the management of low back pain: an up-todate systematic review. Pain Ther. 2018;7:1-12. https://doi.org/10.1007/s40122-018-0099-4.

45. Chou R, Deyo R, Friedly J, Skelly A, Hashimoto R, Weimer $\mathrm{M}$, et al. Nonpharmacologic therapies for low back pain: a systematic review for an american college of physicians clinical practice guideline. Ann Intern Med. 2017;166:493-505. https://doi. org/10.7326/M16-2459.

46. Hall A, Richmond H, Copsey B, Hansen Z, Williamson E, Jones G, et al. Physiotherapist-delivered cognitive-behavioural interventions are effective for low back pain, but can they be replicated in clinical practice? A systematic review. Disabil Rehabil. 2018;40:1-9. https://doi.org/10.1080/ 09638288.2016 .1236155 .

47. Golob ALWJ. Low back pain. Med Clin North Am. 2014;98:405-28. https://doi.org/10.1007/978-3319-43133-8_121.

48. Jarvik JG, Hollingworth W, Heagerty PJ, Haynor DR, Boyko EJ, Deyo RA. Three-year incidence of low back pain in an initially asymptomatic cohort. Spine (Phila Pa 1976). 2005;30:1541-8. https://doi. org/10.1097/01.brs.0000167536.60002.87.

49. Tarabeih N, Kalinkovich A, Shalata A, Livshits G. Circulating levels of visceral adipose tissue-derived serine protease inhibitor (vaspin) appear as a marker of musculoskeletal pain disability. Diagnostics. 2020.

diagnostics10100797. 